\title{
Carbon Dioxide based Power Generation in Renewable Energy Systems
}

\author{
Pramod Kumar $^{1}$ and Kandadai Srinivasan ${ }^{2 *}$ \\ ${ }^{1}$ Department of Mechanical Engineering \\ ${ }^{2}$ Interdisciplinary Centre for Energy Research \\ Indian Institute of Science \\ Bangalore 560012 India \\ *Also with School of Mechanical and Chemical Engineering, \\ University of Western Australia, Crawley WA 6009
}

\begin{abstract}
After a substantial impact on refrigeration, carbon dioxide $\left(\mathrm{CO}_{2}\right)$ is gaining considerable attention as a working fluid for thermal power generation. This can be attributed mainly to its excellent heat transfer properties and compactness of components arising from its high density. It has the merit of being amenable to operation in sub-, trans- or super-critical Brayton cycle modes. However, inhibiting factors are high pressures needed when operated in trans- or supercritical cycles and the work of compression eroding most of the work of expansion in subcritical cycle operation. Some of the lacunae of $\mathrm{CO}_{2}$ such as high work of compression can be alleviated by using non-mechanical means such as thermal compression using the adsorption technique either for partial compression in high pressure Brayton cycles or for total compression in low pressure cycles. $\mathrm{CO}_{2}$ has also been proposed as an additive to flammable hydrocarbons such that their flammability can be suppressed and yet retaining their other desirable thermodynamic qualities. This review explores the potential and limitations of thermodynamic
\end{abstract}


cycles where either $\mathrm{CO}_{2}$ is used alone or as a component in mixture of working fluids. Inter alia, it also highlights the issues of regulation of load management using the efficiency-specific power output plane. When used as a blending component, pinch point in the regenerators affects the cycle performance. The objective is to identify research and developmental challenges involving $\mathrm{CO}_{2}$ as a working fluid specifically for solar power generation.

Key words: Solar thermal power, supercritical $\mathrm{CO}_{2}$, Brayton cycle, Rankine cycle, thermal compression, mixtures with $\mathrm{CO}_{2}$, heat exchangers 


\section{Introduction}

Productivity whether it be agricultural, industrial or commercial is given enormous importance in developing countries as a path to prosperity. Availability of high grade energy, and specifically electrical power is intricately interlinked to productivity. While demand for the former continues to grow at a very rapid rate, environmental issues are inhibiting large scale (at several 100's of MW level) generation of electricity using commonly opted resources such as hydro-, fossil fuel or nuclear. As a result, more governments are turning to renewable energy sources for electricity. Among them, solar energy is the most sought after. The quickest way of electrifying has been through photovoltaics, though, long term sustainability of this option is also to be weighed vis-a-vis use of materials like tellurium, indium and cadmium which are in limited supply and some of them may be associated with health hazards [1]. Comparatively, solar thermal based electricity generation has only a limited penetration. Most of them use concentrated solar energy for generating steam with the rest of the processes being as in a Rankine cycle [2]. Organic Rankine cycle (ORC) power plants, with working fluids other than water, powered by waste heat or solar thermal energy have also been explored at a few 10's MW level and there are several in operation too [3]. One of the main concerns in ORC power plants is the direct greenhouse gas emission arising out of some of the working fluids (such as R-245fa) which have a high global warming potential (GWP). Environmental impact of solar technologies are also often assessed because there are several issues that need to be considered to establish their viability [4]. A notable feature of solar thermal electricity is that no exotic materials are required in their hardware.

For servicing settlements which are quite far from conventional electrical grid, distributed localized power generation is quite attractive because it obviates losses occurring from long 
distance transmission followed by local distribution of electricity. Steam based solar thermal power plants become unviable at 100 's of $\mathrm{kW}$ or smaller levels. ORC power plants need to be operated with working fluids which are either flammable such as propane or toxic such as ammonia if GWP issue has to be addressed. The other option is to search for alternate cycles, eg: Brayton. Air is the most sought after working fluid which needs high temperatures -such as those obtainable from combustion of natural gas. With solar energy as the thermal source where temperature levels are at best $800^{\circ} \mathrm{C}$, a large fraction of the turbine work needs to be allocated to the compressor. It is a common knowledge from thermodynamics that to realize a large energy output, one requires a large enthalpy change of the working fluid which can be either brought about by pressure or temperature changes (or both) with temperature effect being much stronger than the pressure effect. It is apparent that the engineering community is challenged to come up with cycles and working fluids for generating solar thermal electricity using totally environmentally friendly disposition.

On the other hand, looking at the end user of energy, among which is refrigeration and air conditioning industry, natural working fluids are in the lime light with carbon dioxide $\left(\mathrm{CO}_{2}\right)$ emerging as a good choice from every indicator of environmental performance [5]. One must hasten to add that even this sector has been cautious in promulgating this fluid because of its high operating pressure requirements and also higher work of compression compared to halocarbon refrigerants in vogue. More notably, the inhibition arises from transcritical operation of refrigeration cycle and the lack of trained manpower in this area. It is logical to infer that, if $\mathrm{CO}_{2}$ consumes more power during compression than other working fluids, it should also deliver more power while expanding in the same region. Incidentally, $\mathrm{CO}_{2}$ as a Rankine cycle working fluid has been in the reckoning of nuclear power industry for over a decade [6-9]. More recently, 
that option now seems to be applicable even in the renewable energy sector because of the possibility of generating concentrated solar power at temperature in excess of $500^{\circ} \mathrm{C}[10-14]$. This paper reviews the work that has been in progress in this area and presents an overview of prospects and limitations of this option. How the lacuna of high operating pressures can be overcome by using low pressures and thermal compression is also investigated. Another possibility of lowering the upper cycle pressures and simultaneously elevating condensing temperatures by blending $\mathrm{CO}_{2}$ with flammable hydrocarbons is presented. The latter option takes into account the requirement of suppressing the flammability of hydrocarbons and yet retaining their positive thermodynamic features. While the general focus of this paper is on thermodynamic aspect, the fall outs of some of promising choices from the heat transfer point of view are also highlighted.

\section{2. $\mathrm{CO}_{2}$ as a Standalone Working Fluid in Brayton Cycle}

$\mathrm{CO}_{2}$ as a working fluid has a wide domain of operation whether it be for refrigeration or power generation. For refrigeration, it is in vogue as a primary working fluid in sub-critical and transcritical zones. It is also used as a secondary refrigerant in supermarket applications. In view of peculiarities of this refrigerant, Srinivasan et al. [15] proposed the temperature-exergy plane for obtaining a better perspective of the cycle than the conventional pressure-enthalpy plane. In the area of power generation also $\mathrm{CO}_{2}$ has a very wide operational domain, namely in sub-, transand super-critical pressure ranges as Brayton cycle working fluid or even as transcritical Rankine cycle where the heat sink temperatures can be lower than its critical point of about $31^{\circ} \mathrm{C}$. Garg et al. [16, 17] have used representation of these cycles on pressure-enthalpy and temperature- 
entropy planes. Fig. 1 shows such possibilities. Srinivasan et al. [18] proposed a two intensive property coordinate system of sound velocity and pressure, the basic premise being that useful processes (in this case expansion) would occur in the decreasing direction of sound velocity. Accordingly, an alternate plane for representing these cycles is shown in Fig.2. These representative cycles are merely chosen to show a qualitative comparison without any reference to whether or not they are optimal. The direction of decreasing sound velocity during expansion is evident for all the three modes of $\mathrm{CO}_{2}$ Brayton cycles. However, a peculiarity of the supercritical cycle is that the isobaric heat addition process seems to be in the decreasing direction of sound velocity unlike in the other two cases. It also arises because of the compression isentrope being much steeper than the expansion one on this plane. This is also the case with the pressure-enthalpy plane. Further, there is an overshoot which is due to the sound velocity going through a minimum along some of the isobars as shown in Fig. 3. A generalized sound velocity-pressure plane for $\mathrm{CO}_{2}$ in the zone of interest is shown in Fig.4. In Brayton cycles the compression process is viewed as a collateral liability. In fact, Garg et al. [16] show that the ratio of expansion to compression work is as low as 1.5 in the sub-critical region and marginally increases to just over 2 in the transcritical region. However, there is an appreciable reduction in the compressor work in the supercritical cycle albeit with congruent penalty of much higher operating pressures.

Another interesting feature of $\mathrm{CO}_{2}$ Brayton cycles is that the optimal expansion ratios are quite small compared to those in Rankine cycles or high temperature air Brayton cycles. In the case of sub-critical operation it is as low as just over 2 and even in the trans-critical region it is under 3 [16] . However, in the supercritical region it raises up to about 4 for a low pressure of 
$\sim 83$ bar. But this increase in the expansion ratio, which has a symbiotic benefit of enhanced work output, is neutralized by impractical high side operating pressures of 300 bar or higher.

A patent of Osgerby [19] describes a wide spectrum of possibilities from fully supercritical to a combination of supercritical and transcritical condensing cycles. A common feature is two stage compression and expansion. A wholly supercritical operation has been shown with heat source temperatures as high as $1500^{\circ} \mathrm{C}$ and as low as $520^{\circ} \mathrm{C}$. The operating pressures range from critical to 200 bar. One of the embodiments of this patent is a cycle (Fig. 5) where after expansion and regeneration, the flow stream is bifurcated at 8 . One stream of the working fluid operates in the Brayton cycle regime (0-9-0) and the other in transcritical Rankine cycle (8-10-11-1-8).

In solar thermal power systems, one aims to work with maximum efficiency because the cost of the energy collection system, namely the collector field, is far higher than the power block. However, $\mathrm{CO}_{2}$ Brayton cycle operations are laden with deficits of either low expansion ratio, or high operating pressures. The consequence of low expansion ratio compared to conventional gas turbine cycles is that turbine outlet temperatures are significantly large. The enthalpy associated with it is invariably recovered by using a regenerator for preheating the compressor discharge. Perhaps, one could argue that the actual heat input in the solar receiver reduces and hence its size. But, at the time of start still the entire heat has to be given from some source or the other. Garg et al. [16] also analyzed the fraction of heat recovered in the regenerator to the net work output of various cycles. For $\mathrm{S}_{-} \mathrm{CO}_{2}$ cycles it is more than $15 \%$ and for other cycles it is somewhat lesser. Indeed, a real picture of the heat appropriation is visualized through entropy generation in various components and it emerges that the heat exchanger systems- the regenerator and the gas precooler- are the largest sources for it [16, 17]. 
Chacategui et al. [13] elucidate that an $\mathrm{S}-\mathrm{CO}_{2}$ cycle has many advantages when operating at high cycle pressures of 225 bar and source temperatures $>1000 \mathrm{~K}$, among them being their superior efficiency compared to supercritical steam cycles. They also assert that if such pressures have been used in steam cycles, there is no reason why it cannot be so for $\mathrm{S}-\mathrm{CO}_{2}$. The added advantage is compact power block due to low specific volume of the latter. Enthalpy of low pressure stream remaining after recovery in the regenerator can further be used by dovetailing with another ORC for which this remaining heat acts as a heat source. A common conclusion of Chacategui et al. [13] and Dostal et al. [7] is that instead of simple Brayton cycle, a recompression cycle delivers a better performance if heat is available in temperature $>500^{\circ} \mathrm{C}$.

All the foregoing studies uniformly find that operational readiness is a shortcoming for $\mathrm{CO}_{2}$ Brayton cycles. Also there is a clear lack of awareness and trained personnel to handle the situations arising in design and operation of these systems, particularly high pressures and temperatures, despite the fact that they are already in vogue with supercritical steam power plants. Another technological issue that needs to be settled is the design of heat transfer equipment which need a good data base of correlations for designers. This is still work in progress although considerable progress has been made to date [7, 13]. Certain amount of trial and error is inevitable which brings in financial constraints.

The seemingly positive aspect of $\mathrm{S}-\mathrm{CO}_{2}$ cycles of very small components because of low specific volumes at which the cycle operates has a flip side of the need for very high rotational speeds of the turbine. Ma and Turchi [20] report that for a power of $300 \mathrm{~kW}$ the turbine rotor is just $40 \mathrm{~mm}$ in diameter for a flow rate of $3.5 \mathrm{~kg} / \mathrm{s}$, but has to rotate at 125,000 rpm. Dostal [6] points out that the compactness of the power block is negated by voluminous heat exchangers in the form of regenerators and gas coolers. Turchi et al. [12] give a good summary of the role of 
effectiveness and loop pressure losses in heat exchangers in recuperated Brayton cycles over and above their contribution to cost. The recuperated heat can be many times larger than that absorbed from the primary heat source. Future work is needed to bring combined effects of heat exchanger size and pressure drop into the cycle performance analyses. In order to minimize these deficiencies, printed circuit/ micro-channel heat exchangers are proposed. In such a case, cleanliness of $\mathrm{CO}_{2}$ and the heat transfer fluid become paramount and it has to be devoid of any contaminants such as oil/suspended particles. But the exact effect can only be quantified in situ. In addition, because of environmental problems of use of cooling towers (eg: legionella regulations), many industries are dispensing with it by switching to air cooled heat exchangers. In the case of $\mathrm{CO}_{2}$ Brayton cycles, this inducts some other contingencies because the compressor performance is quite sensitive to gas inlet temperature [21], which essentially is the temperature one can achieve that is as close to ambient temperature dictated by diurnal and seasonal fluctuations. Singh et al. [22] further reaffirm the strong interdependence of mass flow rate, compressor operating parameters and power output in $\mathrm{S}-\mathrm{CO}_{2}$ solar power systems. They stress the need for in tandem assessment of three important entities, namely, i) regulation of amount of charge for stable turbine inlet temperature and power output during summer operation, ii) control of compressor inlet conditions for sustained fully supercritical operation and improved net-power output during winter and iii) sizing of the hot and cold-sides of $\mathrm{S}^{-\mathrm{CO}_{2}}$ loop because of variable densities under widely fluctuating dynamic operating conditions.

\subsection{Transcritical non-condensing Brayton cycle}

Garg et al. [23] propose an option of operating with $\mathrm{CO}_{2}$ in the Brayton cycle with a subcritical lower cycle pressure. This non-condensing cycle $\left(\mathrm{TN}-\mathrm{CO}_{2}\right)$ is devoid of the 
consequences of high pressures at high temperatures because they are well below 150 bar which is due to a reduction in the optimum expansion ratio as well. However, this benefit accrues at a premium, with a drop in the efficiency which is not too significant. For example, their analysis shows that for a $900 \mathrm{~K}$ source temperature, a low side pressure of $50 \mathrm{bar}$, the optimal high side pressure is 112.5 bar which yields an efficiency of just under $28 \%$ whereas for the same source temperature, a S-CO $-\mathrm{CO}_{2}$ cycle has an upper cycle pressure of $\sim 225$ bar and yields an efficiency of $30.5 \%$. It is evident that a small sacrifice of efficiency is worthwhile for reducing the risks associated with operating at double the pressures.

Another feature of transcritical Brayton cycles is their amenability to load regulation. In solar operations, seldom it is possible to secure a constancy of heat source temperature. As this changes, the point of maximum efficiency also changes implying that the corresponding optimal expansion ratios also change. Garg et al. [23] analyzed the performance of both $\mathrm{TN}^{-\mathrm{CO}_{2}}$ and S$\mathrm{CO}_{2}$ cycles on efficiency- specific work output plane. This two path function coordinate system is shown to provide a lot of useful information on operational aspects such as load regulation and associated drop in efficiency. It was shown that a $\mathrm{TN}-\mathrm{CO}_{2}$ cycle has a wider range of load regulation adoptability than $\mathrm{S}-\mathrm{CO}_{2}$ cycle at any given temperature, although at the cost of a larger drop in efficiency when operating away from the optimal efficiency point.

\subsection{CO2 Subcritical Brayton cycle with thermal compression}

$\mathrm{CO}_{2}$ as a subcritical Brayton cycle mode is unlikely to make any impact because of low optimal expansion ratios $(\sim 2)$ and the fact that the compression work is more than half of the turbine output even with heat source at $800 \mathrm{~K}$ [16]. This demerit can be overcome if compression can be achieved by means other than turbine work. Dutta et al. [24] proposed a novel scheme 
wherein the compression is achieved using low grade thermal energy, which in this case can be from a field of flat plate or evacuated tubular collectors. The adsorption route was proposed for this process which is based on the phenomena of pressure and temperature dependent adsorption characteristics of some highly microporous activated carbons for $\mathrm{CO}_{2}$. They also point out that efficiencies are as low as $4 \%$ for $\mathrm{CO}_{2}$ if the heat source and sink are at 100 and $35^{\circ} \mathrm{C}$ respectively for both compression and expansion. Optimal pressure ratios are also about 2.3 and are virtually independent of low side operating pressure in the low side pressure range of 2-55 bar. But, if low grade heat source can be used only for thermal compression and another high grade heat source such as from a concentrating field can be used for preheating the compressed $\mathrm{CO}_{2}$, a complete delinking of compressor and expander work will happen. This will in turn widen opportunity for deriving as much work as possible from the turbine by expanding down to compression inlet pressure. However, because of poor adsorption characteristics of activated carbons for $\mathrm{CO}_{2}$ at near atmospheric temperature and pressure [25], the low side pressure of $\mathrm{CO}_{2}$ cycle needs to be boosted to 10-30 bar level. Yet, for single stage thermal compression, there is also a theoretical limit to maximum pressure that can be generated (Fig. 6), according to the condition that

$$
\mathrm{C}\left(\mathrm{p}_{\mathrm{L}}, \mathrm{T}_{\mathrm{ads}}\right)=\mathrm{C}\left(\mathrm{p}_{\mathrm{H}}, \mathrm{T}_{\mathrm{des}}\right)
$$

where $\mathrm{C}$ is the uptake $(\mathrm{kg} / \mathrm{kg})$.

However, at that $\mathrm{p}_{\mathrm{H}}$ value the throughput of the adsorbers will be zero corresponding to uptake efficiency being zero [26]. In the case of Maxsorb $\mathrm{III}+\mathrm{CO}_{2}$ system this pressure is about $40 \mathrm{bar}$ for an adsorption pressure of $10 \mathrm{bar}, \mathrm{t}_{\mathrm{ads}}=30^{\circ} \mathrm{C}$ and $\mathrm{t}_{\mathrm{des}}=100^{\circ} \mathrm{C}$. The uptake efficiency is defined as the ratio of uptake difference across which an adsorber operates under actual and ideal conditions [27]. The ideal condition is the one under which the effect of void volume is absent and equilibrium conditions exist [27]. To realize a meaningful throughput Srinivasan et al. [28] 
recommend that a minimum uptake efficiency of $40 \%$ must be targeted. Because of this limitation thermal compression ratio diminishes further and is found to remain fairly constant at about 2.3 [23] which is again comparable to the optimal expansion ratio for a sub-critical conventional Brayton cycle. The thermal efficiency of adsorption compression Brayton cycle against specific work per unit mass of activated carbon required is shown in Fig. 7. In this figure $\Delta h$ is the specific work per unit mass of $\mathrm{CO}_{2}$ and $\Delta C$ is uptake in $\mathrm{kg}$ of $\mathrm{CO}_{2}$ per $\mathrm{kg}$ of activated carbon. This plot is generated for same cycle temperature limits of 35 and $100^{\circ} \mathrm{C}$ and for $2<\mathrm{p}_{\mathrm{L}}<55$ bar. However, if larger compression ratios are desired, it is possible to adopt two stage thermal compression. A typical transcritical Brayton cycle with two stage thermal compression is shown in Fig. 8 [29]. Here $\mathrm{p}_{I}$ is an intermediate pressure and an intercooling will be necessary to cool the discharge gas emerging from low stage adsorber at $\mathrm{p}_{\mathrm{I}}$ from $\mathrm{t}_{\mathrm{des}}$ to $\mathrm{t}_{\text {ads }}$. The cycle is shown in Fig. 9. A schematic diagram of a Brayton cycle with two-stage thermal compression is shown in Fig.10. However, the draw backs of such a compression is a necessity of a large number of adsorbers and an enormous parasitic heating inventories demanded by the adsorbent, adsorber metal container and the heat of adsorption over and above the change in enthalpy of $\mathrm{CO}_{2}$. It may be possible to eliminate the regenerator after expansion if the expander downstream temperature is equal to or below the discharge temperature of the compression process which will essentially be the low grade heat source temperature.

Koyama et al. [30] proposed an innovative method of using hybrid compression of thermal and mechanical means for $\mathrm{CO}_{2}$ for refrigeration applications. This technique can easily be used for sub-critical Brayton cycles as well. A schematic of such a cycle with low stage thermal and high stage mechanical compression is shown in fig.11. It will be an interesting exercise to determine what optimal turbine expansion ratios will be because only a small fraction 
of it will be absorbed by the compressor. One has to optimize also the sequence of compression as to which method has to be used in the lower stage. Further, the inter-stage pressure needs to be optimized for maximum net work output of the cycle.

For adsorption based thermal compression, there is an imminent need for experimental isotherm data covering pressures of the order of 10's of MPa and temperatures well in excess of $100^{\circ} \mathrm{C}$. Because such an application was not perceived to date, activated carbon $+\mathrm{CO}_{2}$ adsorption measurements covered only temperatures well below $360 \mathrm{~K}$, although pressure range extended up to $14 \mathrm{MPa}[25,31,32]$.

\section{3. $\mathrm{CO}_{2}$ as a Rankine cycle fluid}

A lot of research has occurred with $\mathrm{CO}_{2}$ as a Rankine cycle working fluid where heat rejection can occur at subcritical temperatures implying ambient temperatures being quite low (well below critical temperature of $\mathrm{CO}_{2} \sim 31^{\circ} \mathrm{C}$ ). Desired upper cycle operating pressures can also be $<100$ bar. But in this Rankine cycle, heat addition is in the supercritical region. Angelino and Invernizzi [33] report an analysis of such a cycle with liquefied natural gas (LNG) as the heat sink. This cycle has the potential of covering the vast range from -50 to $600^{\circ} \mathrm{C}$ with a single fluid. This indeed is a highly viable option in locations endowed with abundant direct solar radiation and where there is a need to convert $\mathrm{LNG}$ in to compressed natural gas $(\mathrm{CNG})$. They also report the application of a transcritical condensing cycle for which the heat sink can be the low temperature sea water which has been the topic of ocean thermal energy too.

Yamaguchi et al.'s [34] work covers a range of $\sim 90$ bar and $165^{\circ} \mathrm{C}$, the latter being achievable in high quality evacuated tubular collectors. Their laboratory simulation tests yielded good results but were not conclusive enough in the absence of a turbine which was replaced by 
an expansion valve and a heat exchanger. Zhang et al. [35] confirm that $\mathrm{CO}_{2}$ is the best Rankine cycle working fluid among ammonia, water and HFC 134a in temperature range up to about $175^{\circ} \mathrm{C}$, although in this range even transcritical $\mathrm{CO}_{2}$ cycle has an efficiency under $12 \%$. For this reason, Chen et al. [36] do not favor $\mathrm{CO}_{2}$ as a transcritical Rankine cycle working fluid for heat source temperatures less than $433 \mathrm{~K}$. An analogous conclusion is arrived at by Chen and Lundqvist [37] who attribute the weak performance to drastic changes in the properties of $\mathrm{CO}_{2}$ during the heat addition process. Garg et al. [17] compare irreversibilities in $\mathrm{CO}_{2}$ and steam Rankine cycles and conclude that at heat source temperatures below $1000 \mathrm{~K}$ the $\mathrm{CO}_{2}$ cycle has a fairly larger irreversibility due to high turbine exhaust temperatures and inevitable use of a regenerator which contributes the maximum irreversibility.

Chen et al. [38] also bring out a salient point that only considering the thermodynamic efficiencies of cycles could be misleading, because the power output and cycle thermal efficiency cannot be maximized at the same point of when utilizing a certain heat source. This is also one of the conclusions of Cayer et al. [39] in a context of a free heat source like industrial waste gases where the focus should be on maximising the specific net output rather than the thermal efficiency. This aspect has been investigated in greater detail by Garg et al. [23]. For the transcritical Rankine cycle the efficiency vs specific net work output plane is shown in Fig. 12. As seen here for heat source temperatures over $700 \mathrm{~K}$, the points of maximum efficiency and maximum specific work occur for high side pressures well over 300 bar. If the cycle pressures are to be limited, then sub-optimal operation becomes inevitable. The working plane of two path functions, namely the cycle efficiency and the specific work output was also used by Chacategui et al. [13]. However, their range of analysis did not extend to pressures where maximum work output and efficiency can be visualized. 
All the $\mathrm{CO}_{2}$ cycles suffer from poor performance under off design conditions [14]. The key role of performance of the compressor is already highlighted. When used in concentrated solar power without energy storage, vagaries in sunshine cause wide fluctuations in turbine inlet temperatures under which both power output and efficiency decline sharply. Garg et al. [23] have mapped it for various operating conditions.

\section{4. $\mathrm{CO}_{2}$ as a blend with other working fluids}

In all the afore mentioned applications of $\mathrm{CO}_{2}$ as a Brayton cycle working fluid, the negative features are either high operating pressures if used in mechanical compression or large heat inventories if used with thermal compression. Thermal compression also is still conceptual and it is unlikely that in the immediate future any practical power plants will be built. If used as a Rankine cycle fluid, the sink temperatures have to be well below critical point of $\mathrm{CO}_{2}$. In this context, it is worthwhile exploring $\mathrm{CO}_{2}$ as a component in mixtures of working fluids. Being a good suppressor of flammability, it can be used along with flammable hydrocarbons which are themselves known to be good working fluids in power generation. Their collateral disadvantage can be obviated by suitably mixing with $\mathrm{CO}_{2}$. Garg et al. [40] have used this philosophy and evaluated some of the possible mixtures with saturated hydrocarbons such as propane, butane, pentane etc. A similar approach of blending hydrocarbons with some halocarbon refrigerants has also been proposed in the past [41-43]. It is important that all components of the mixture be environmentally friendly. Invernizzi and Stelt [43], however, proposed a mixture of benzene and $\mathrm{CO}_{2}$. An important contribution to this method is from $\mathrm{Li}$ and $\mathrm{Ma}$ [44] who found out that most hydrocarbon and $\mathrm{CO}_{2}$ blends achieve an optimal efficiency at a $\mathrm{CO}_{2}$ mass fraction of 0.5 . Because of non-isothermal condensation the exergetic and thermal efficiency are enhanced. Only butanes were the alkanes covered in their investigation. Garg et al. [40] covered other alkanes 
such as propane and isopentane. Their analysis proposes that a $30 \%$ mole fraction of $\mathrm{CO}_{2}$ is adequate to suppress flammability. Such a mixture yields a glide range of slightly over $20^{\circ} \mathrm{C}$ for propane $\mathrm{CO}_{2}$ mixtures and $80-100^{\circ} \mathrm{C}$ for isopentane $\mathrm{CO}_{2}$ mixtures. The latter could be run as a conventional Rankine cycle with substantial heat addition occurring in the two-phase region and also in the regenerator. In the case of propane $\mathrm{CO}_{2}$ mixtures the upper pressure isobar happens to be supercritical. Yet, even in the case of these mixtures the expansion ratios are seldom greater than 3 implying that substantial turbine tail side heat recovery needs to be effected in a regenerator. In order to make propane $\mathrm{CO}_{2}$ mixture as a serious contender, Garg et al. [45] consider an appropriate non-flammable mixture which has a high critical point and also normal boiling point lower than typical ambient temperatures encountered in tropical countries. For example, for a typical condensation temperature of $\sim 35^{\circ} \mathrm{C}$, a mole fraction mixture of $48.5 \%$ propane and $51.5 \% \mathrm{CO}_{2}$ the critical temperature is $\sim 62^{\circ} \mathrm{C}$ and the corresponding critical pressure is 68.3 bar. However, for a condensing pressure of $~ 50$ bar, the optimum expansion ratio is found to be $>6$ implying a high side pressure in excess of 300 bar, which is again burdened with the same disadvantage of a $\mathrm{S}-\mathrm{CO}_{2}$ cycle.

\section{Heat transfer issues}

There will be at least three heat exchangers in the $\mathrm{CO}_{2}$ Brayton cycle: i) the regenerator where the high pressure streams emerging from the compressor is heated by the hot low pressure exhaust stream of the expander, ii) enthalpy enhancement of the high pressure stream by the concentrated solar heat derived at the receiver and iii) heat rejection in the gas cooler before $\mathrm{CO}_{2}$ enters the compressor. Since the expansion ratios are quite small, the low pressure stream at expander exit is quite warm (of the order of $500^{\circ} \mathrm{C}$ ), whereas the high pressure stream from the 
discharge of compressor is often of the order of $100^{\circ} \mathrm{C}$. Thus, there is enormous potential for heat recovery. Because of large pressure dependence of specific heat, the temperature change of the high pressure stream in the regenerator tends to be much smaller than for the low pressure stream. A recent review by Dutta [47] summarises the important issues to be addressed in the design of all these heat exchangers. Several configurations of regenerator have been suggested, the prominent ones being tube-in-tube type [48], printed circuit heat exchangers (PCHE) and microchannel heat exchangers (MCHE) [49]. Considerable amount of work on heat transfer in supercritical $\mathrm{CO}_{2}$ has been reported mainly for refrigeration gas cooling applications [50]. Whether there are any peculiarities due to combined effects of pressures and temperatures well above the critical point is still a topic of research. Enhancement/curtailment of heat transfer in supercritical $\mathrm{CO}_{2}$ seems to be a cumulative effect of sharp changes in the thermophysical properties across a particular temperature range. Thermal conductivity, viscosity and density decline sharply around the critical point $\left(\sim 31^{\circ} \mathrm{C}\right)$. This should affect the design of the gas cooler upstream of the compressor. The specific heat has a more peculiar behavior. It rises sharply, but the magnitude of enhancement and its steepness reduce as temperature increases. All these effects decrease with increasing supercritical pressure to become insignificant at about one and a half times the critical value, confirming that they are caused by the rapid near critical variation in physical properties [51]. This feature suggests that the unit used for actual enthalpy enhancement of $\mathrm{CO}_{2}$ before its entry to expander could be designed in the conventional way. Zhang and Yamaguchi [48] observed a substantial enhancement in heat transfer and attributed it to i) thinner thermal boundary layer than in the case of water and ii) the decrease in viscosity and the increase in heat capacity and iii) velocity and temperature fields not reaching a fully developed state. Pioro et al. [52] compared various correlations for supercritical heat transfer and suggest that 
most of them can be used for preliminary estimations of heat transfer in tubes and bundles. However, no one correlation is able to describe deteriorated or improved heat transfer in tubes. In another review article Duffey and Pioro [53] aver that there are all three possibilities of heat transfer, namely normal (as occurring in other fluids), a zone where it is worse than usual heat transfer and a zone where it is enhanced due to properties of supercritical $\mathrm{CO}_{2}$. Flow orientation also seems to make a difference in the magnitude of heat transfer coefficients. In general, there is a distinct possibility of circumferentially non uniform temperatures which are attributable to large variations in density of $\mathrm{CO}_{2}$ at conditions prevailing in the core and near the wall. Deteriorated conditions seem to be dominant at high heat fluxes and low mass flow rates and turbulence promoters need to be inserted in these zones.

Garg et al. [16] show that a substantial amount of energy is exchanged in the regenerator and the irreversibilities in this unit and final gas cooler are quite large in $\mathrm{S}-\mathrm{CO}_{2}$ cycles. Hence it is imminent that these two units deserve a critical design. Pulsed jet impingement cooling, perhaps, could be considered for these two units. A schematic arrangement is shown in fig. 13.

Pinch point in the regenerator is a limiting issue in general in all Rankine/Brayton cycle power generation methods. The two fluid temperatures approach each other with driving force for heat transfer. Conboy et al. [54] report that this can occur under two general conditions: i) when the hot-stream temperature reaches the inlet temperature of the cold-stream which can happen if the heat exchanger is over designed or at off-design conditions in a counter current heat exchanger if the heat capacities of the two fluids greatly differ as in the case of $\mathrm{S}-\mathrm{CO}_{2}$ case and ii) when one of the fluid streams approaches its critical point (or a phase change), causing large changes in heat capacity, for which, the heat transfer at the location of the pinch point can still be very high, because the local heat transfer coefficient can increase close approach to the 
critical point (or phase change). In the case of a regenerator heat capacity of the high pressure $\mathrm{CO}_{2}$ stream is larger than in the low pressure leg by a factor of 2 . Its avoidance is the very reason the $\mathrm{S}-\mathrm{CO} 2$ recompression cycle has gained favour over the simple recuperated Brayton cycle.

Important conclusion of Garg et al. [40] is that as the number of carbon atoms in alkanes decreases, their blend with $\mathrm{CO}_{2}$ moves the pinch point to the colder end of the regenerator. The shift of the pinch point towards the warm end of the regenerator is found to be a major cause of irreversibility and accordingly they suggest use of propane $\mathrm{CO}_{2}$ mixture as a possible transcritical Rankine cycle fluid if heat source is available at about $300^{\circ} \mathrm{C}$. Adoptability of this mixture over a wide range of source temperatures is found to be an added advantage. However, the upper limit has to be $<900 \mathrm{~K}$, due to disintegration of propane [46]. A minor advantage of large temperature glides associated with alkanes of larger carbon atoms, despite their association with large irreversibilities, is that the heat recovery can be stretched well in to the two phase dome.

As far as the pressure drop is concerned, it seems to play only a limited role because of the fact that the isotherms at the operating levels are quite steep (p-h plane), such that the changes in enthalpy are extremely small. Even $2-5$ bar drops of the low side pressure and up to 10 bar on the high side have marginal effect on the changes in enthalpy. Hence, many designs have focused predominantly on the heat transfer rather than the pressure drop aspects. The work of Suzuki et al. [55] shows that when PCHE is used, discontinuous S-shaped fins in flow paths provide a fivefold reduction in the pressure drop without compromising the heat transfer. They ascribe this feature to a superior uniform velocity profile in the flow area and elimination of reverse flows and eddies that occur around bends corners of zigzag flow channels in conventional PCHE. Perhaps, this configuration can be used in the channels shown in fig. 13. 


\section{Concluding remarks}

In this paper range of possibilities of using $\mathrm{CO}_{2}$ as a working fluid for solar thermal power generation have been reviewed. Although, in complete supercritical state it has several benefits, inhibiting factors are high operating pressures and need of higher source temperatures. In the transcritical non-condensing mode, with some sacrifice in efficiency more amenable turbine inlet pressures can be realized. Complete sub-critical operation is impractical since the work of expansion is virtually consumed by the compressor. But if thermal compression is adopted in two stages or hybrid compression of mechanical and thermal means is resorted to, a subcritical cycle could be feasible. However, this needs to be supported through extensive data on $\mathrm{CO}_{2}$ adsorption on adsorbents such as activated carbon. As a transcritical Rankine cycle working fluid, $\mathrm{CO}_{2}$ needs condensing temperatures below about $20^{\circ} \mathrm{C}$ which makes it a difficult choice in tropical regions. However, positive features of $\mathrm{CO}_{2}$ can still be used as a component in a mixture with hydrocarbons. Here again, non-isothermal phase change leads to some design limitations, which are possible to be accommodated. A good design of all the heat exchangers is paramount to successful implementation of the cycles.

\section{Acknowledgement}

This research is based upon work supported by the Solar Energy Research Institute for India and the U.S. (SERIIUS) funded jointly by the U.S. Department of Energy subcontract DE AC3608G028308 (Office of Science, Office of Basic Energy Sciences, and Energy Efficiency and Renewable Energy, Solar Energy Technology Program, with support from the Office of International Affairs) and the Government of India subcontract IUSSTF/JCERDCSERIIUS/2012 dated 22nd Nov. 2012. In addition, the authors would also like to thank 
Professors J.A.White and S. Velasco of University of Salamanca, Spain for helping with the development of sound velocity- pressure plane of Brayton cycles for $\mathrm{CO}_{2}$. 


\section{References}

[1] V. Fthenakis, Sustainability of photovoltaics: a case of thin film solar cells, Renew. Sustainable Energy Rev. 13(2009) 2746-2750.

[2] D. Mills, Advances in solar thermal electricity technology, Solar Energy 76 (2004) 19-31.

[3] R.R. Sonde, Low-grade (waste) energy conversion: science and technological challenges, Proc. Indian National Sci. Acad. 81 (2015) 717-723.

[4] T.Tsoutsos, N. Frantzeskaki, V. Gekas, Environmental impacts from the solar energy technologies, Energy Policy, 33(2005) 289-296.

[5] K. Srinivasan, P. Sheahen, C.S.P Sarathy, Optimum thermodynamic conditions for upper pressure limits of transcritical carbon dioxide refrigeration cycle, Int. J. Refrigeration 33 (2010) 1395-1401.

[6] V. Dostal, A supercritical carbon dioxide cycle for next generation nuclear reactors, D.Sc Thesis, Massachusetts Institute of Technology (2004)

[7] V. Dostal, P. Hejzlar, M.J. Driscoll, The supercritical carbon dioxide power cycle: comparison to other advanced power cycles, Nuclear Technology 154 (2006) 283-301.

[8] A. Moisseytsev, J.J. Sienicki, Investigation of alternative layouts for the supercritical carbon dioxide Brayton cycle for a sodium-cooled fast reactor, Nuclear Eng. Design 239 (2009) 1362-1371.

[9] Y. Ahn, S.J. Bae, M. Kim, S.K. Cho, S Baik, J.I. Lee, J.E. Cha, Review of supercritical $\mathrm{CO}_{2}$ power cycle technology and current status of research and development, Nucl. Eng. Tech.147 (2015) 647-661. 
[10] S.A. Wright, R.F. Radel, M.E. Vernon, G.E. Rochau, and P.S. Pickard, Operation and analysis of a supercritical CO2 Brayton Cycle, Sandia National Laboratories, Report No. SAND2010-0171(2010).

[11] Z. Ma, C.S. Turchi, Advanced Supercritical Carbon Dioxide Power Cycle Configurations for Use in Concentrating Solar Power Systems, Preprint, Supercritical CO2 Power Cycle Symposium Boulder, Colorado, May 24-25, (2011) Conference Paper, NREL/CP-550050787.

[12] C.S. Turchi, Z. Ma, T.W. Neises, M.J. Wagner, Thermodynamic study of advanced supercritical carbon dioxide power cycles for concentrating solar power systems, J. Solar Energy Eng. 135 (2013) 041007,1-7.

[13] R. Chacartegui, J.M. Muñoz de Escalona, D. Sánchez, B. Monje, T. Sánchez, Alternative cycles based on carbon dioxide for central receiver solar power plants, App. Thermal Eng. $31(2011) 872-879$.

[14] M. Atif, F.A. Al-Sulaiman, Performance analysis of supercritical CO2 Brayton cycles integrated with solar central receiver system, The fifth International Renewable Energy Congress, Hammamet, Tunisia, IREC (2014) March 25 - 27, 978-1-4799-2195-9/14, IEEE.

[15] K. Srinivasan, Y.K. Lim, J.C. Ho, N.E. Wijeysundera, Exergetic analysis of carbon dioxide vapour compression refrigeration cycle using the new fundamental equation of state, Energy Conv. Management 44 (2003) 3267-3278.

[16] P. Garg, P. Kumar and K. Srinivasan, Supercritical carbon dioxide Brayton cycle for concentrated solar power, J. Supercritical Fluids 76 (2013) 54-60. 
[17] P. Garg, P. Kumar and K. Srinivasan, P. Dutta, Comparison of CO2 and steam in transcritical Rankine cycles for concentrated solar power, Energy Procedia 49 (2014) 1138 $-1146$.

[18] K. Srinivasan, P. Dutta, S. Velasco, J.A. White, On isentropic lines and isentropic exponents, J. Chem. Thermodynamics 56 (2013) 144-148.

[19] I. Osgerby, Carbon dioxide power cycle, U.S. Patent No. 4,498,289 (1985).

[20] Z. Ma, C.S. Turchi, Supercritical carbon dioxide power cycle configuration for use in concentrating solar power systems, US Patent Application US 20120216536 A1 (2012).

[21] D.J. Chapman, D.A. Arias, An assessment of the supercritical carbon dioxide cycle for use in a solar parabolic trough power plant, Presentation, Abengoa Solar, 2009.

[22] R. Singh, S.A. Miller, A.S. Rowlands, P.A. Jacobs, Dynamic characteristics of a directheated supercritical carbon-dioxide Brayton cycle in a solar thermal power plant, Energy, 50 (2013) 194-204.

[23] P. Garg, P. Kumar, K. Srinivasan, A trade-off between maxima in efficiency and specific work output of super- and trans-critical $\mathrm{CO}_{2}$ Brayton cycles, J. Supercritical Fluids. 98 (2015) 119-126.

[24] P. Dutta, P Kumar, K.C. Ng, S. Srinivasa Murthy, K. Srinivasan, Organic Brayton cycles with solid sorption thermal compression for low grade heat utilization, App. Thermal Eng. 62 (2014) 171-175.

[25] B.B. Saha, S. Jribi, S. Koyama, I.I. El-Sharkawy, Carbon dioxide adsorption isotherms on activated carbons, J. Chem. Eng. Data 56 (2011) 1974-1981. 
[26] K.Srinivasan, M. Prasad, P. Dutta, Activated carbon based adsorption thermal compression systems for cryocooling, refrigeration and gas storage, in: Advances in Adsorption Technology Editors:B.B.Saha and K.C.Ng, (2010) Nova Science Publishers, New York.

[27] B.S. Akkimaradi, M. Prasad, P. Dutta, K. Srinivasan, Effect of packing density and adsorption parameters on the throughput of a thermal compressor, Carbon 40 (2002) 28552859.

[28] K. Srinivasan, N.D. Banker, M. Prasad. B.S. Akkimaradi, Evaluation of sorption compressor performance from isotherm data: application to activated Carbon + nitrogen/HFC 134a systems, In "Thermally Powered Sorption Technology" (Eds) B.B. Saha, A. Akisawa, S. Koyama, Proceedings of International Seminar on Thermally Powered Sorption Technology, Kyushu University, Fukuoka, Japan, December 4-5, 2003, pp 121-133.

[29] N.D. Banker, M. Prasad, K. Srinivasan, Comparative analysis of single and two stage activated carbon +HFC134a refrigeration systems, Carbon 2004, American Carbon Society, Rhode Island.

[30] S. Koyama, B.B. Saha, A. Chakraborty, K. Kuwahara, K. Srinivasan, CO2 based compression adsorption hybrid: a novel high performance refrigeration and air conditioning device, in: 8th IIR Gustav Lorentzen Conference on Natural Working Fluids, Sorption-1, 2008. Paper No. M2-07, September 7-10, Copenhagen, Denmark.

[31] M. Sudibandriyo, Z. Pan, J.E. Fitzerald, R.L. Robinson Jr., K.A.M. Gasem, Adsorption of methane, nitrogen, carbon dioxide, and their binary mixtures on dry activated carbon at 318.2 K and Pressures up to 13.6 MPa, Langmuir, 19 (2003) 5323-5331. 
[32] F. Dreisbach, R. Staudt, J.U. Keller, High pressure adsorption data of methane, nitrogen, carbon dioxide and their binary and ternary mixtures on activated carbon, Adsorption 5, (1999) 215-227.

[33] G. Angelino, C.M. Invernizzi, Carbon dioxide power cycles using liquid natural gas as heat sink, Appl. Thermal Eng. 29 (2009) 2935-2941.

[34] H. Yamaguchi, X.R. Zhang, K. Fujima , M. Enomoto, N. Sawada, Solar energy powered Rankine cycle using supercritical $\mathrm{CO}_{2}$, Appl. Thermal Eng. 26 (2006) 2345-2354.

[35] X.R. Zhang, H. Yamaguchi, D. Uneno, K. Fujima, M. Enomoto, N. Sawada, Analysis of a novel solar energy-powered Rankine cycle for combined power and heat generation using supercritical carbon dioxide, Renewable Energy 31 (2006) 1839-1854.

[36] H. Chen, D.Y. Goswami, M.M. Rahman, E.K. Stefanakos, Energetic and exergetic analysis of $\mathrm{CO}_{2-}$ and R32-based transcritical Rankine cycles for low-grade heat conversion, Appl. Energy 88 (2011) 2802-2808.

[37] Y. Chen, P. Lundqvist, The $\mathrm{CO}_{2}$ transcritical power cycle for low grade heat recovery discussion on temperature profiles in system heat exchangers, Proc. ASME 2011 Power Conf., POWER2011 July 12-14, 2011, Denver, Colorado, USA, POWER Paper No. 201155075 .

[38] Y. Chen, P. Lundqvist, A. Johansson, P. Platel, A comparative study of the carbon dioxide transcritical power cycle compared with an organic Rankine cycle with R123 as working fluid in waste heat recovery, Appl. Thermal Eng. 26, 2006, 2142-2147.

[39] E. Cayer, N. Galanis, M. Desilets, H. Nesreddine, P. Roy, Analysis of a carbon dioxide transcritical power cycle using a low temperature source, Appl. Energy, 86 (2009) 10551063. 
[40] P. Garg, P. Kumar, K. Srinivasan, P. Dutta, Thermodynamic assessment of carbon dioxide blends with isopentane and propane as working fluids for organic Rankine cycles, Appl. Thermal Eng. 52 (2013) 439-448.

[41] P. Garg, P. Kumar, K. Srinivasan, P. Dutta, Evaluation of isopentane, R-245fa and their mixtures as working fluids for organic Rankine cycles, Appl. Thermal Eng. 51 (2013) 292300.

[42] J. Song, C.-W Gu, Analysis of ORC (Organic Rankine Cycle) systems with pure hydrocarbons and mixtures of hydrocarbon and retardant for engine waste heat recovery, Appl. Thermal Eng. 89 (2015) 693-702.

[43] C.M. Invernizzi, T. van der Stelt, Supercritical and real gas Brayton cycles operating with mixtures of carbon dioxide and hydrocarbons, Proc. Inst. Mech. Engineers, Part A: J. Power Energy, 2012, DOI: 10.1177/ 0957650912444689.

[44] B. Dai, M. Li, Y. Ma, Thermodynamic analysis of carbon dioxide blends with low GWP (global warming potential) working fluids-based transcritical Rankine cycles for low-grade heat energy recovery, Energy 64 (2014) 942-952.

[45] P. Garg, P. Kumar, K. Srinivasan, P. Dutta, Elevation of heat rejection temperature in transcritical condensing cycles using $\mathrm{CO}_{2}$ +propane mixtures, Proceedings of ASME Turbo Expo 2014, GT2014,Turbine Technical Conference and Exposition, June 16 - 20, 2014, Düsseldorf, Germany.

[46] A.M. Kamiński, J. Sobkowski, High temperature thermal decomposition of propane, Reaction Kinetics and Catalysis Letters, 11 (1979) 391-397. 
[47] P. Dutta, Heat transfer challenges in novel power cycles for concentrating solar power, Keynote Lecture KN17, International Heat Transfer Conference (IHTC-15), 10-15 Aug 2014, Kyoto, Japan.

[48] X.R. Zhang, H. Yamaguchi, Forced convection heat transfer of supercritical $\mathrm{CO}_{2}$ in a horizontal circular tube, J. Supercritical Fluids 41 (2007) 412-420.

[49] T.L. Ngo, Y. Kato, K. Nikitin, T. Ishizuka, Heat transfer and pressure drop correlations of microchannel heat exchangers with S-shaped and zigzag fins for carbon dioxide cycles, Exp. Thermal Fluid Sc. 32 (2007) 560-570.

[50] S.S. Pitla, D.M. Robinson, E.A. Groll, S. Ramadhyani, Heat transfer from supercritical carbon dioxide in tube flow: A critical review, HVAC\&R Research 4(1998) 281-301.

[51] P.J. Bourke, D.J. Pulling, L.E. Gill, W.H. Denton, Forced convective heat transfer to turbulent, Int. J. Heat Mass Transfer 13 (1970) 1339-1348.

[52] I.L. Pioro, H.F. Khartabil1, R.B. Duffey, Heat transfer to supercritical fluids flowing in channels-empirical correlations (survey), Nuclear Eng. Design 230 (2004) 69-91.

[53] R.B. Duffey, I.L. Pioro, Experimental heat transfer of supercritical carbon dioxide flowing inside channels (survey), Nuclear Eng. Design 235 (2005) 913-924.

[54] T. Conboy, S. Wright, J. Pasch, D. Fleming, G. Rochau, R. Fuller, Performance characteristics of an operating supercritical $\mathrm{CO}_{2}$ Brayton cycle, Eng. Gas Turbines Power 134 (2012) 111703.

[55] N. Tsuzuki, Y. Kato, T. Ishiduka, High performance printed circuit heat exchanger, Appl. Thermal Engi.27 (2007) 1702-1707 


\section{List of figures}

Figure 1. Various possibilities of Brayton and Rankine $\mathrm{CO}_{2}$ power cycles.

Figure 2. Sub-, trans- and super-critical $\mathrm{CO}_{2}$ Brayton cycles on sound velocity-pressure plane with $\mathrm{T}_{\mathrm{L}}=30^{\circ} \mathrm{C}, \mathrm{T}_{\mathrm{H}}=600^{\circ} \mathrm{C}$. Legend: Full lines- subcritical $\left(\mathrm{p}_{\mathrm{L}}=10 \mathrm{bar}, \mathrm{p}_{\mathrm{H}}=40 \mathrm{bar}\right)$; broken lines - transcritical $\left(p_{L}=20\right.$ bar, $p_{H}=80$ bar); dotted lines- supercritical $\left(p_{L}=80\right.$ bar, $\mathrm{p}_{\mathrm{H}}=320$ bar). Chain link line- critical isentrope.

Figure 3. Sound velocity- temperature plane for $\mathrm{CO}_{2}$. Legend: --320 bar, $\cdots-200$ bar, - - - - 80 bar.

Figure 4.Sound velocity-pressure plane for $\mathrm{CO}_{2}$ in the region of interest.

Figure 5.Transcritical Rankine-cum- supercritical Brayton cycle embodiments of Osgerby [19]

Figure 6. Representation of limiting high side cycle pressure $\left(\mathrm{p}_{\mathrm{H}}\right)$ with thermal compression.

Figure 7. Thermal compression $\mathrm{CO}_{2}$ Brayton cycle Efficiency - specific work characteristic.

Figure 8. Two stage thermal compression.

Figure 9. Two-stage compression Brayton cycle on the T-s diagram. 1-2: Thermal compression low stage. 3-4: can be thermal compression upper stage or mechanical compression.

Figure 10. Schematic arrangement of a 2-stage thermal compression subcritical Brayton cycle.

Figure 11. Schematic arrangement of a hybrid compression Brayton cycle.

Figure 12. Efficiency- specific work plane for transcritical $\mathrm{CO}_{2}$ Rankine cycle with condensation at $300 \mathrm{~K}$.

Figure 13. A possible configuration of regenerator for enhancing heat transfer through pulsed impinging jets. 


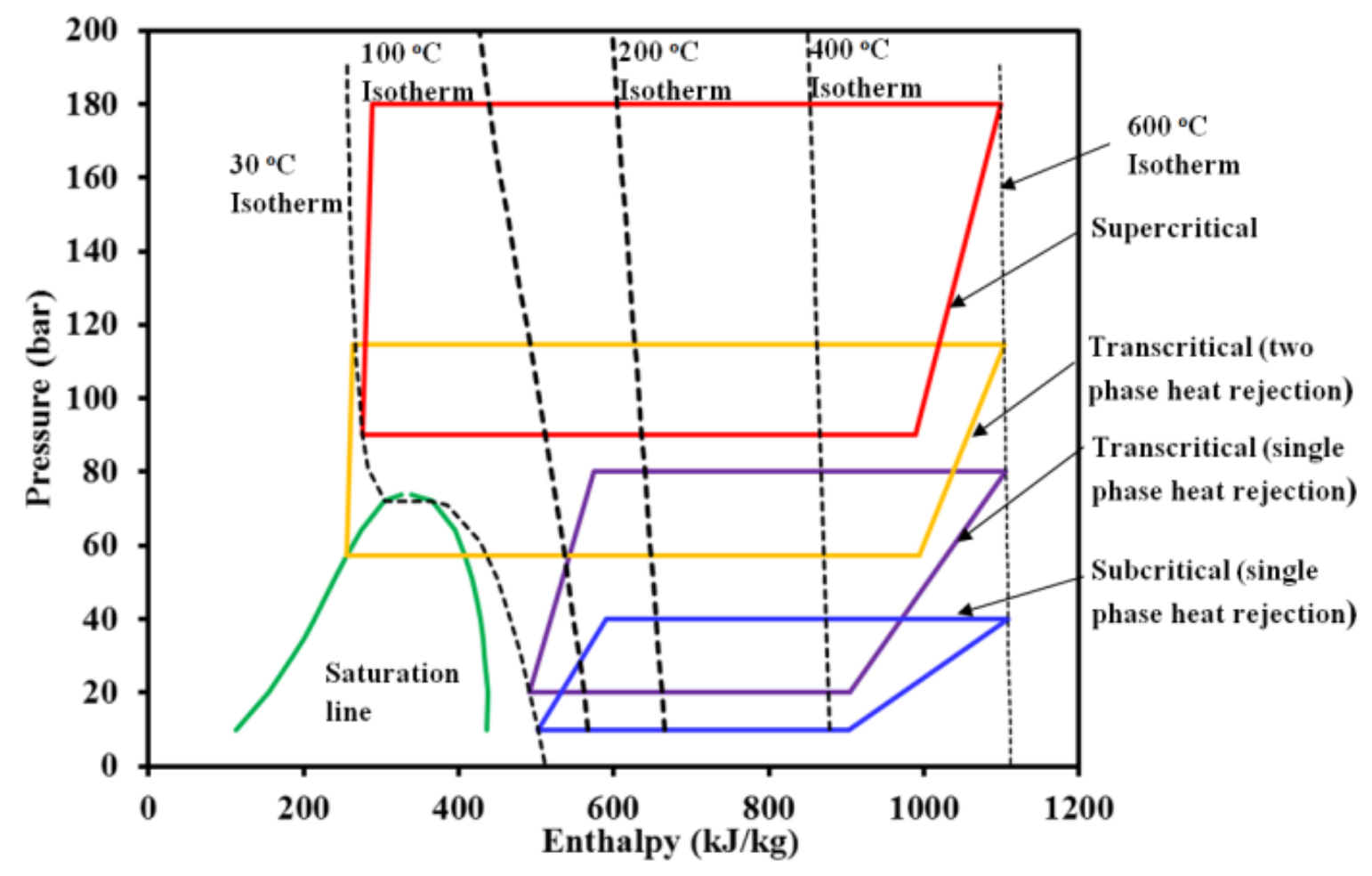

Figure 1. Various possibilities of Brayton and Rankine $\mathrm{CO}_{2}$ power cycles. 


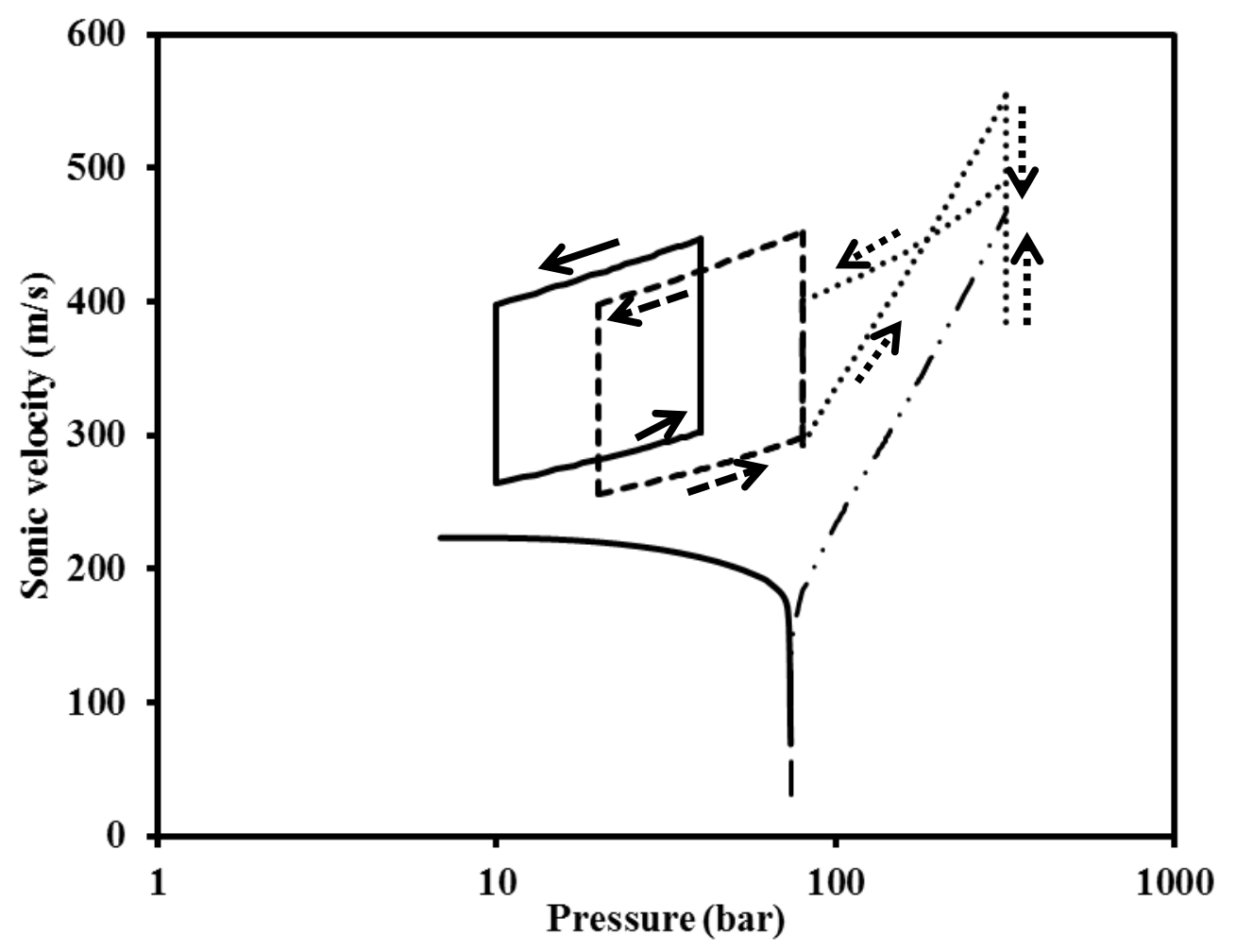

Figure 2. Sub-, trans- and super-critical $\mathrm{CO}_{2}$ Brayton cycles on sound velocity-pressure plane with $\mathrm{T}_{\mathrm{L}}=30^{\circ} \mathrm{C}, \mathrm{T}_{\mathrm{H}}=600^{\circ} \mathrm{C}$. Legend: Full lines- subcritical $\left(\mathrm{p}_{\mathrm{L}}=10\right.$ bar, $\mathrm{p}_{\mathrm{H}}=40$ bar); broken lines transcritical ( $\mathrm{p}_{\mathrm{L}}=20$ bar, $\mathrm{p}_{\mathrm{H}}=80 \mathrm{bar}$ ); dotted lines- supercritical ( $\mathrm{p}_{\mathrm{L}}=80$ bar, $\mathrm{p}_{\mathrm{H}}=320$ bar). Chain link line- critical isentrope. 


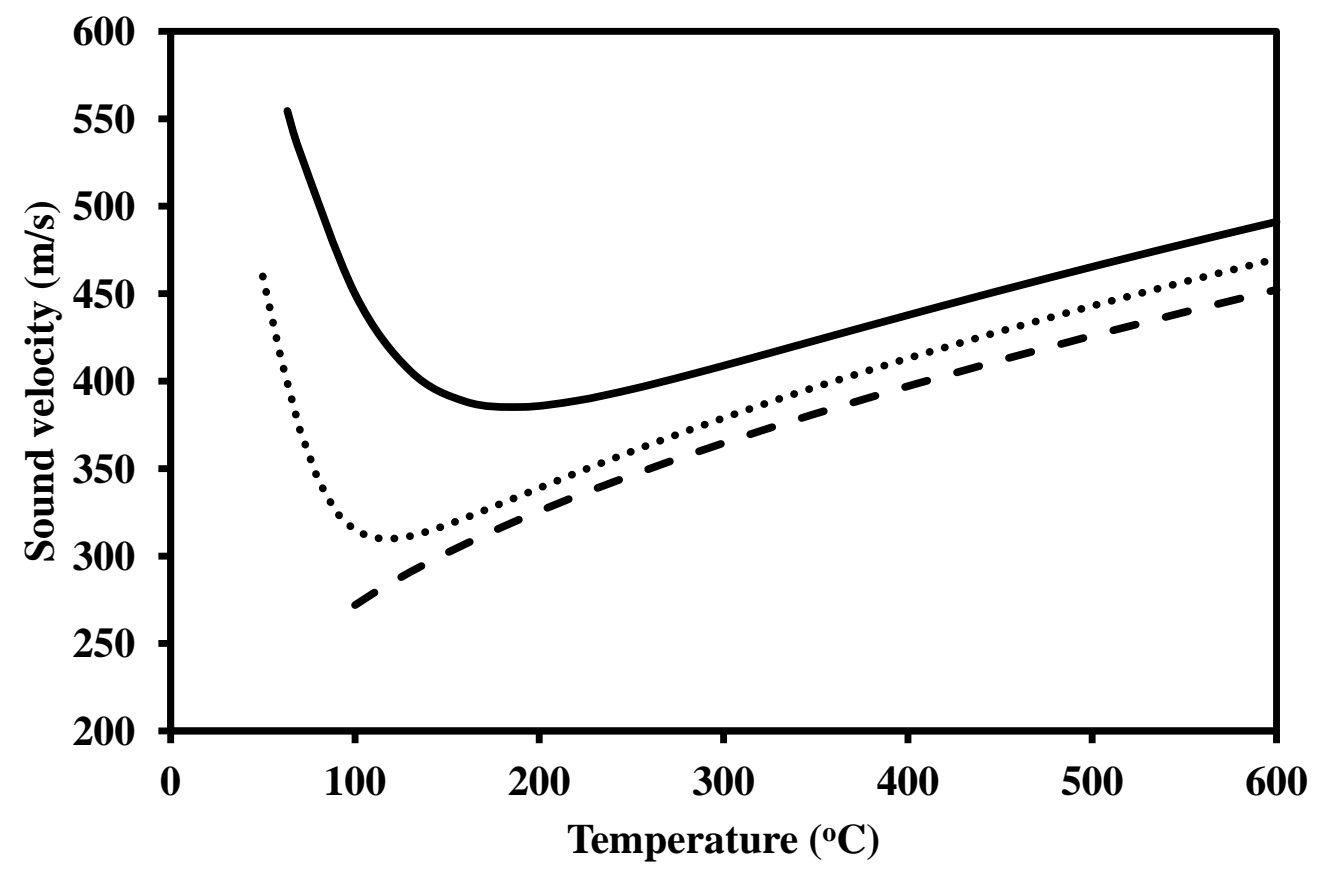

Figure 3. Sound velocity- temperature plane for $\mathrm{CO}_{2}$. Legend: --320 bar, $\cdots-200$ bar, - . - 80 bar. 


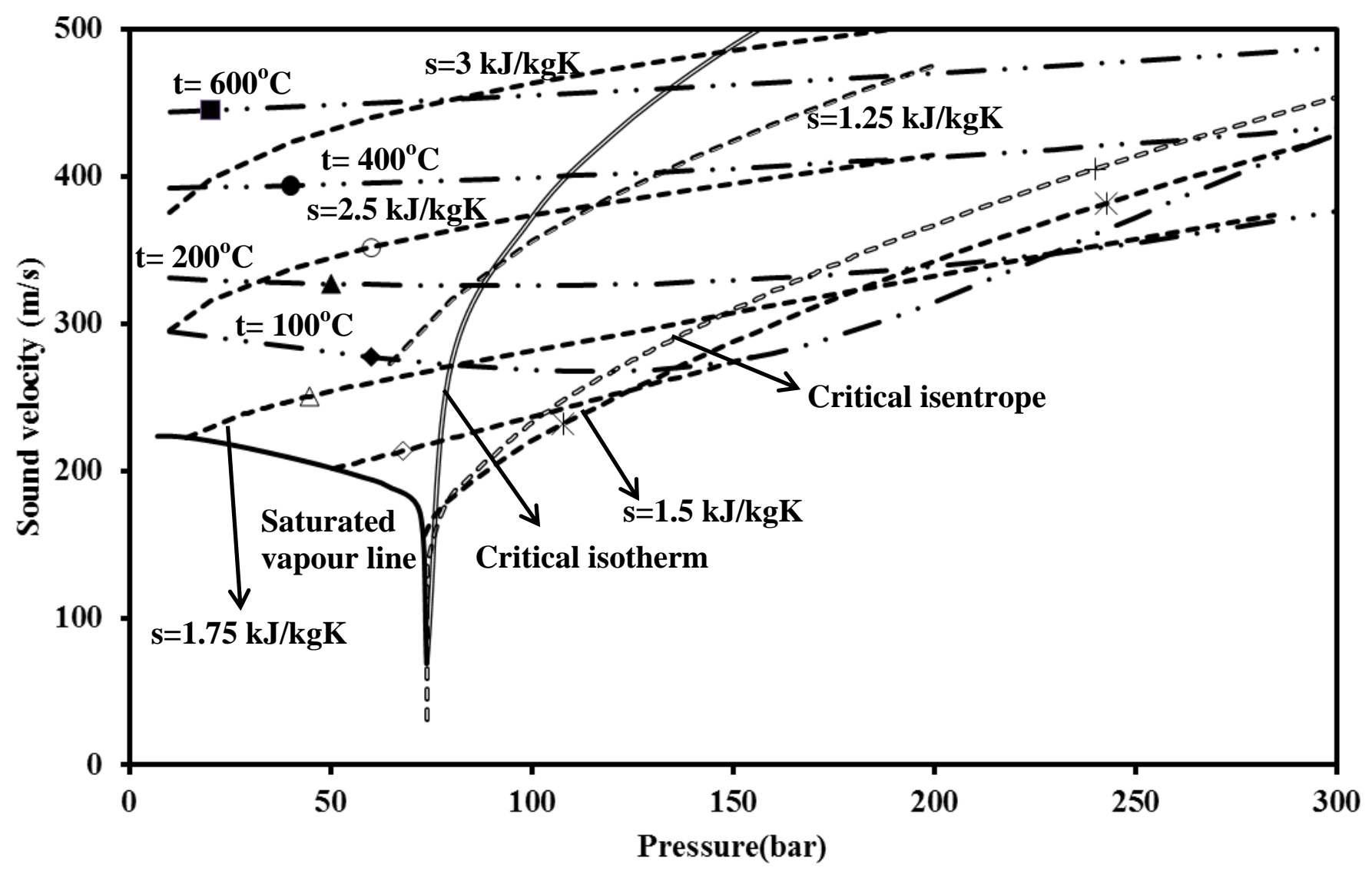

Figure 4. Sound velocity-pressure plane for $\mathrm{CO}_{2}$ in the region of interest 


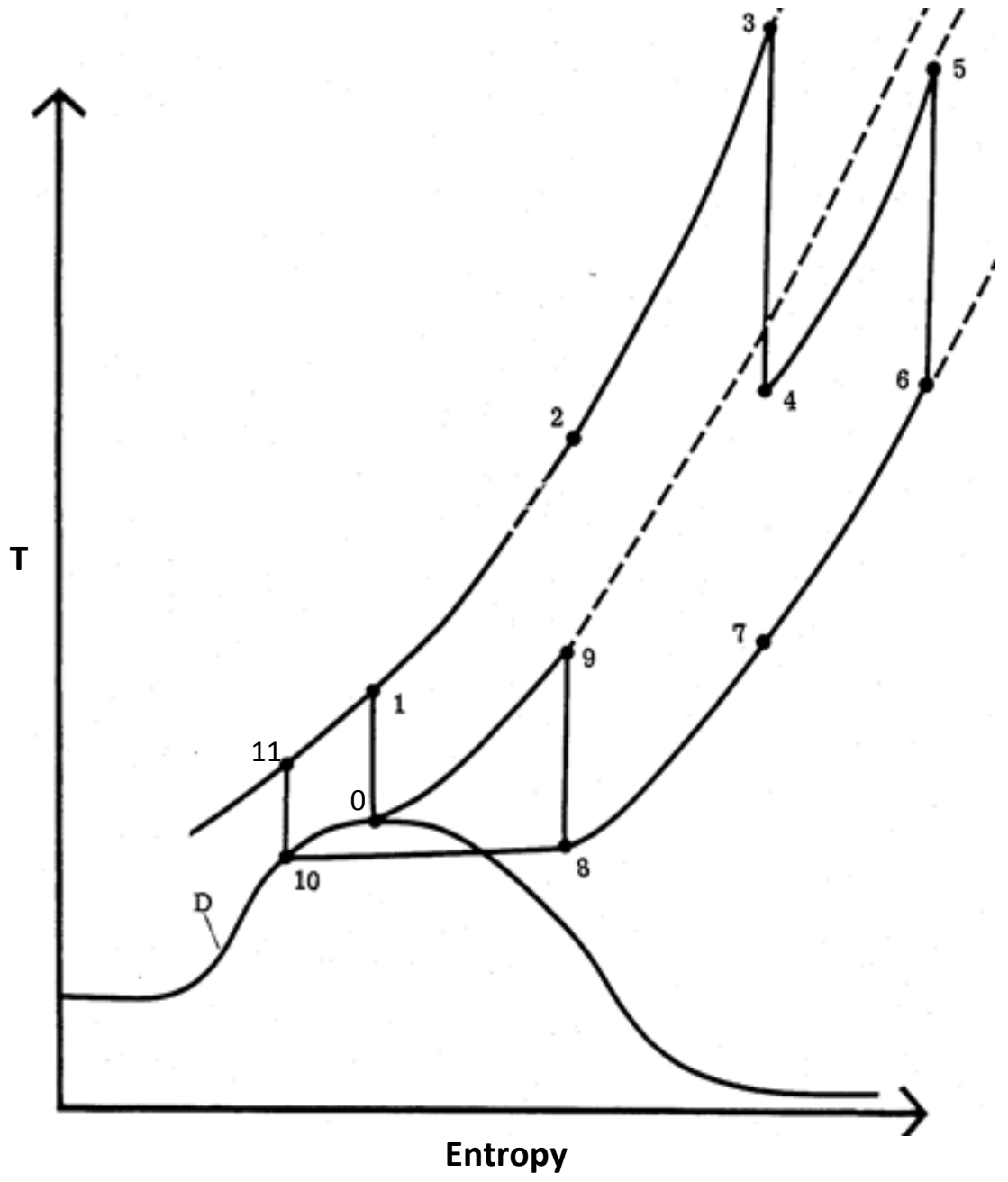

Figure 5. Transcritical Rankine-cum- supercritical Brayton cycle embodiments of Osgerby [19] 


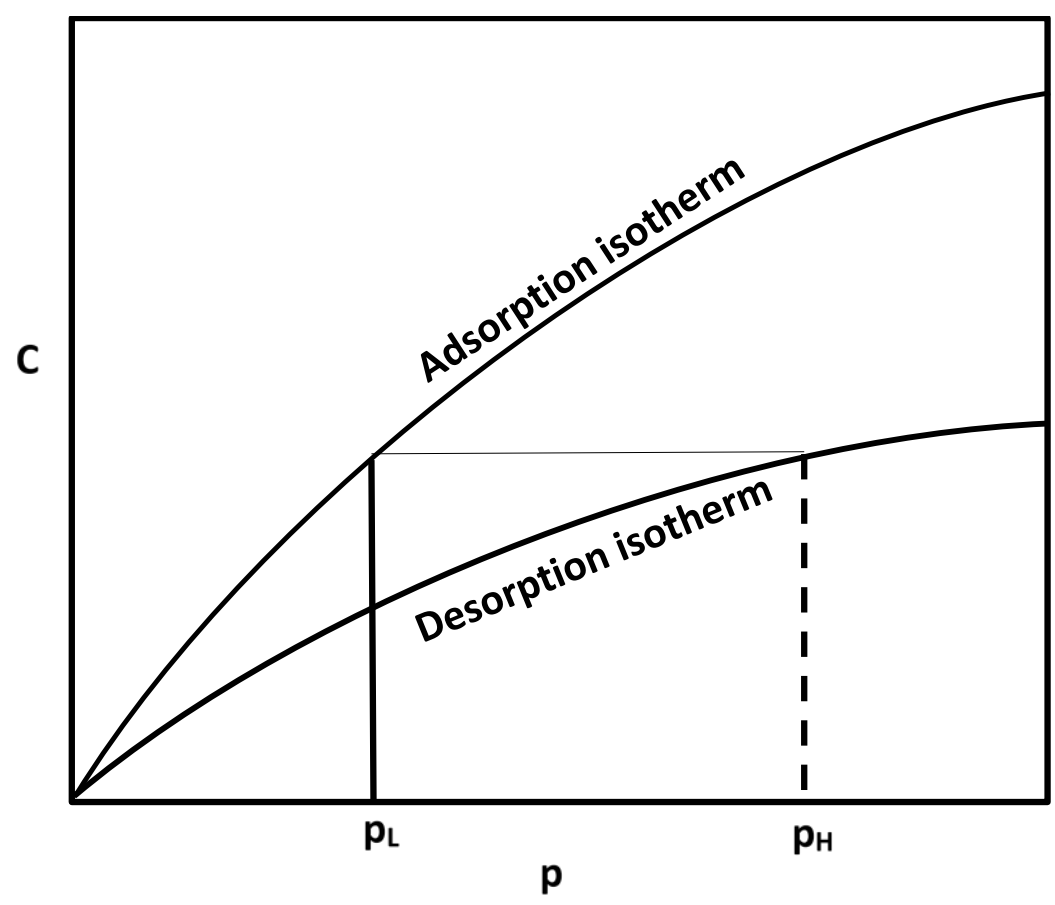

Figure 6. Representation of limiting high side cycle pressure $\left(\mathrm{p}_{\mathrm{H}}\right)$ with thermal compression. 


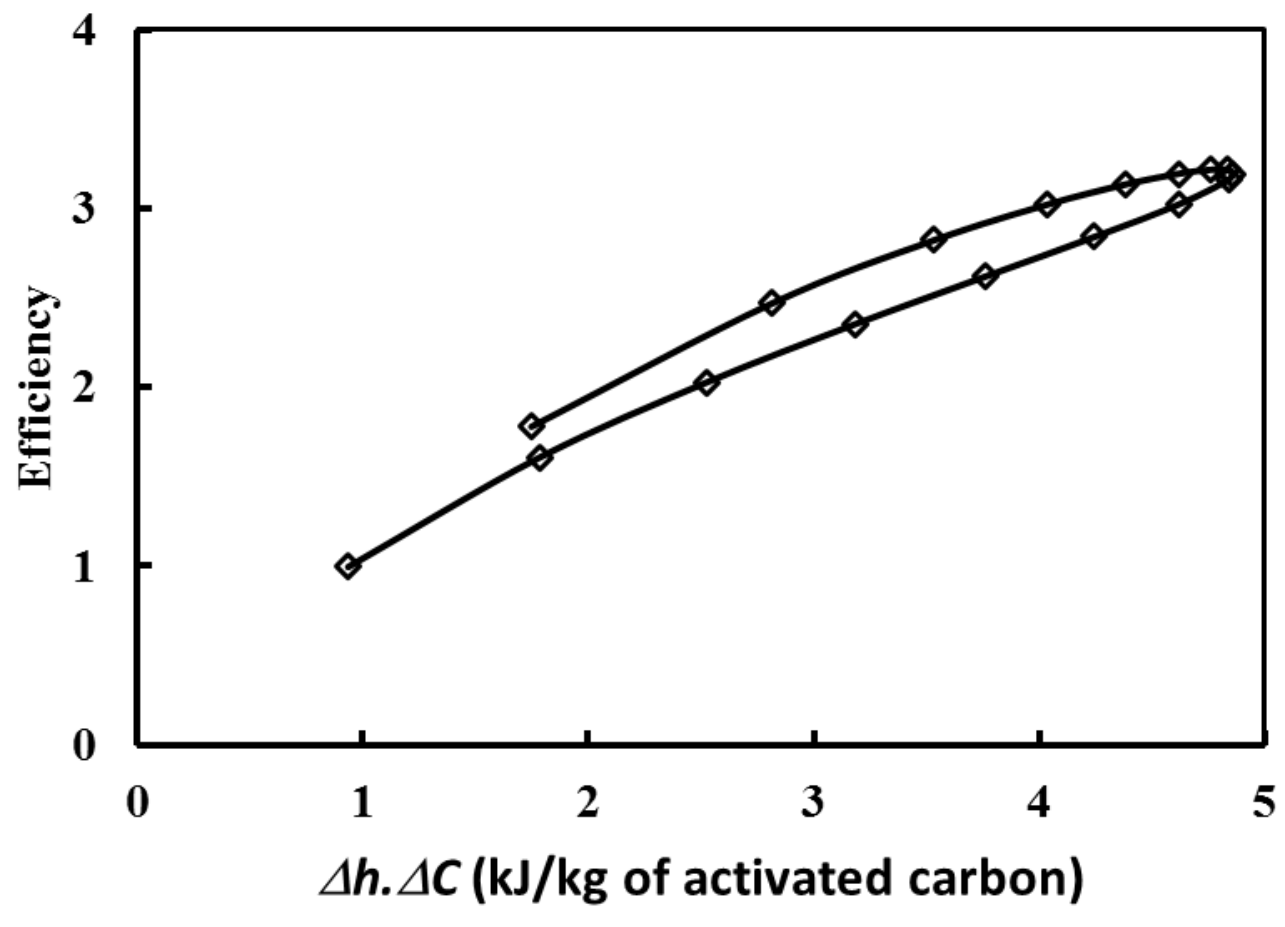

Figure 7. Thermal compression $\mathrm{CO}_{2}$ Brayton cycle Efficiency - specific work characteristic. 


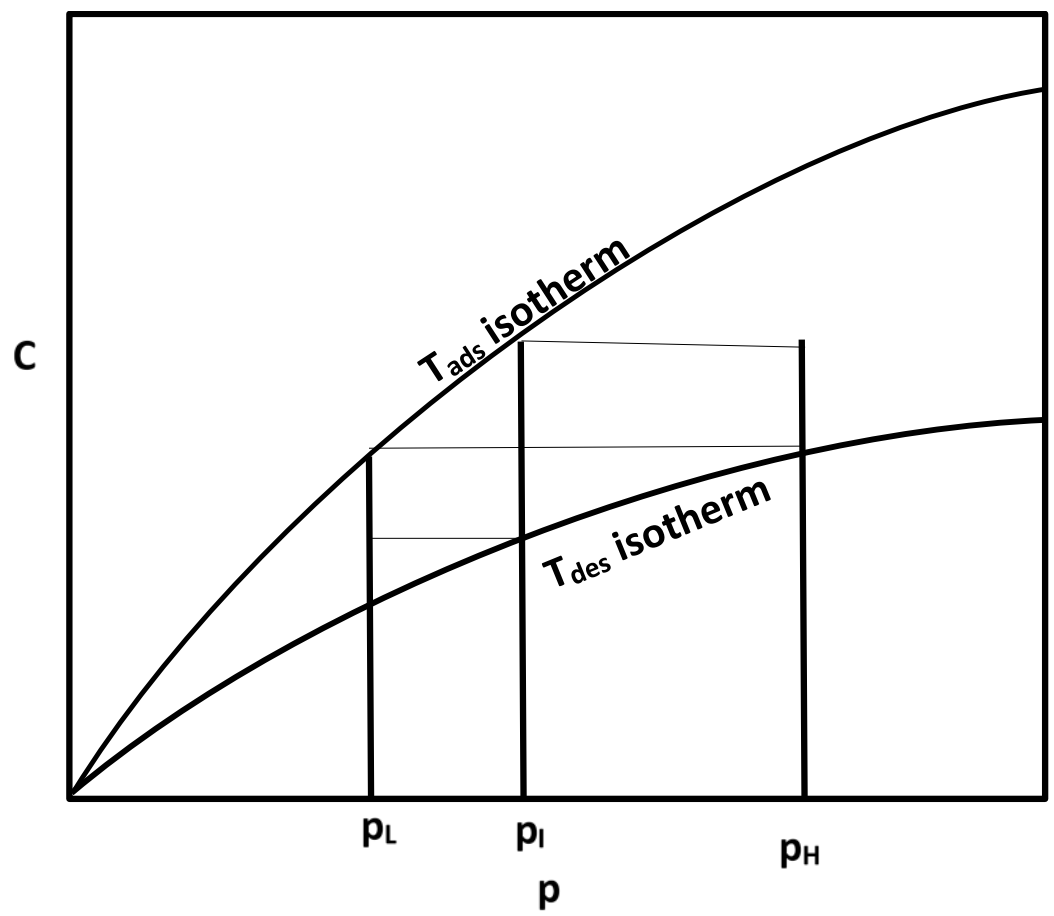

Figure 8. Two stage thermal compression. 


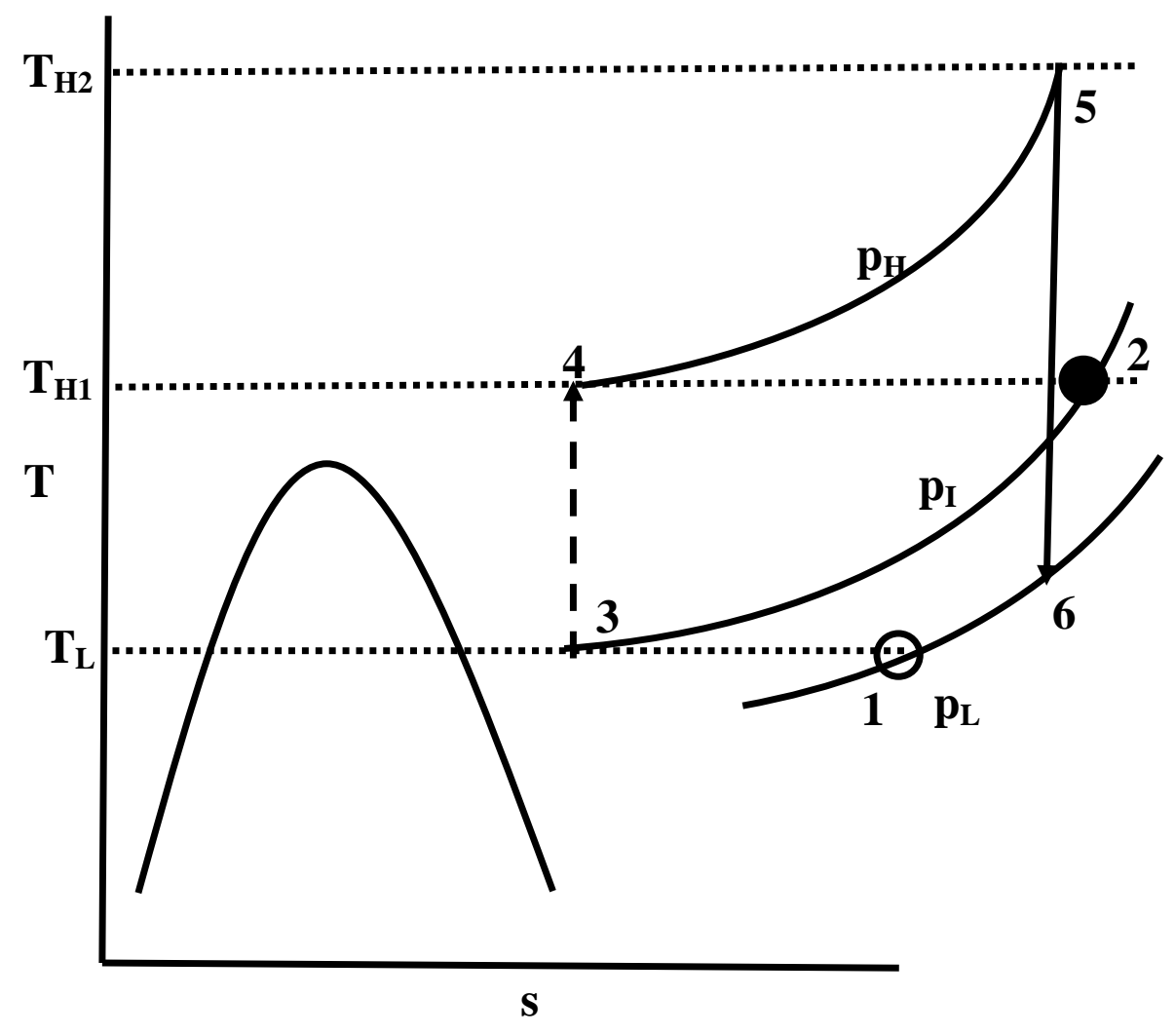

Figure 9. Two-stage compression Brayton cycle on the T-s diagram. 1-2: Thermal compression low stage. 3-4: can be thermal compression upper stage or mechanical compression 


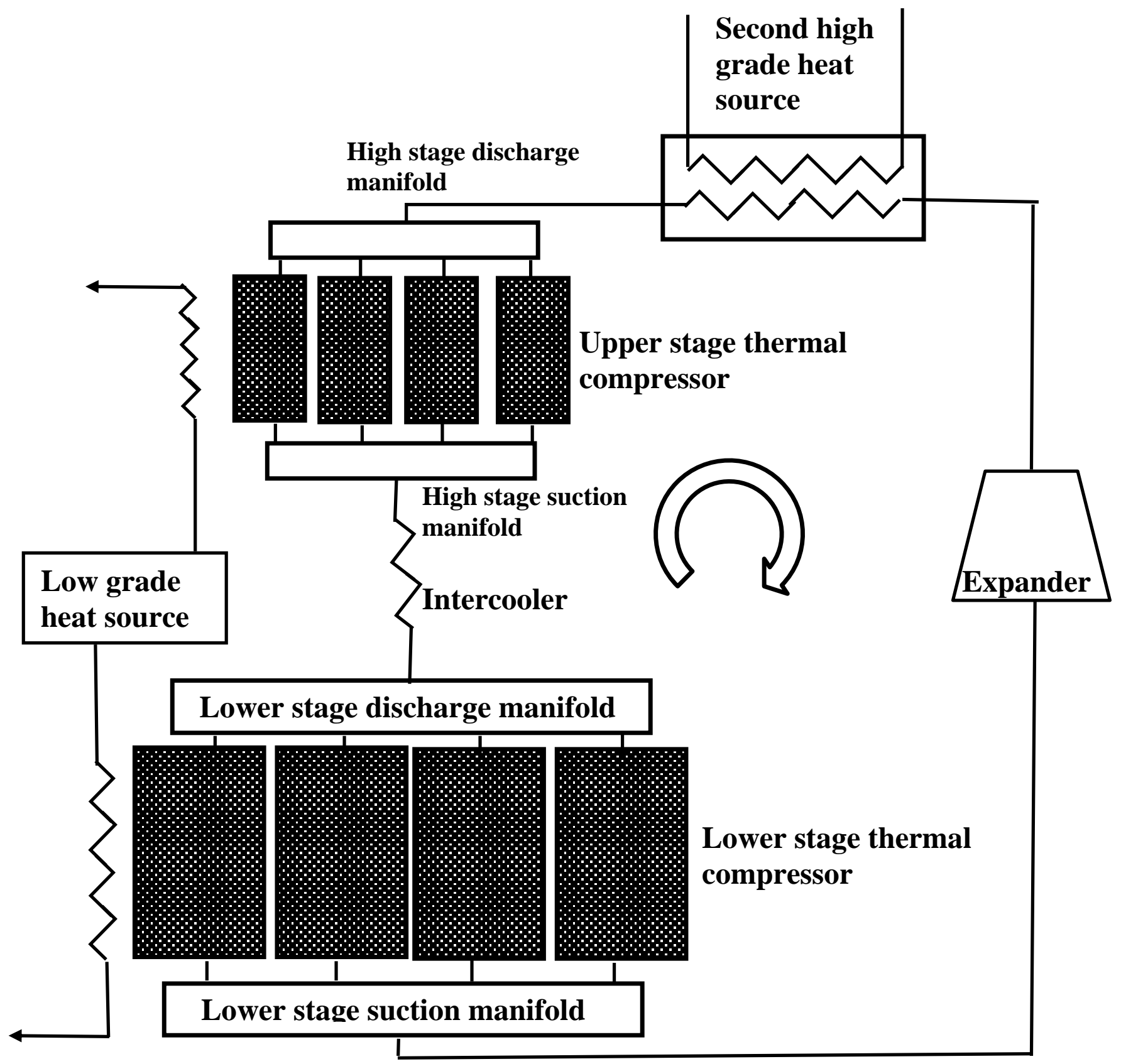

Figure 10. Schematic arrangement of a 2-stage thermal compression subcritical Brayton cycle 


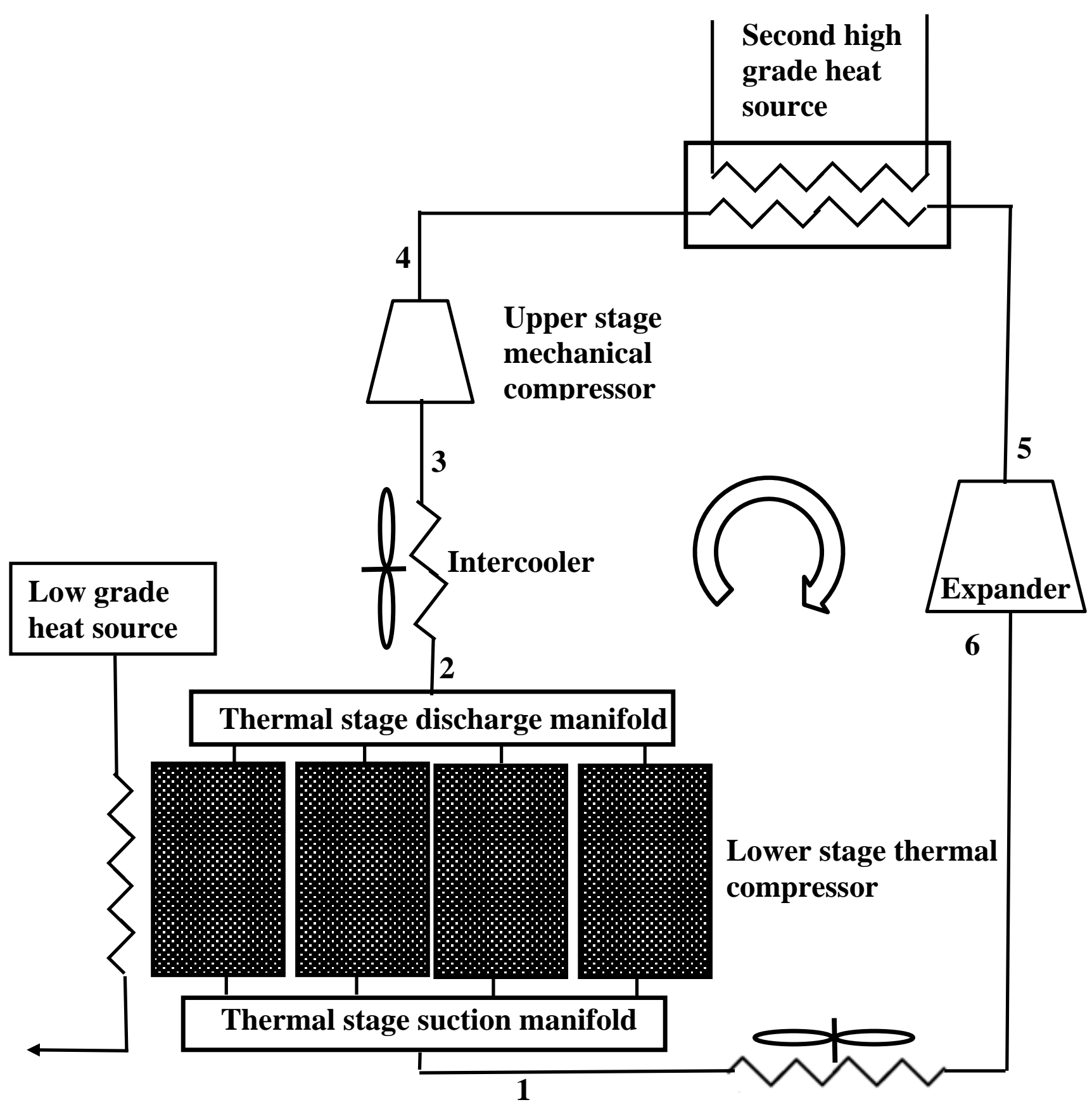

Figure 11. Schematic arrangement of a hybrid compression Brayton cycle 


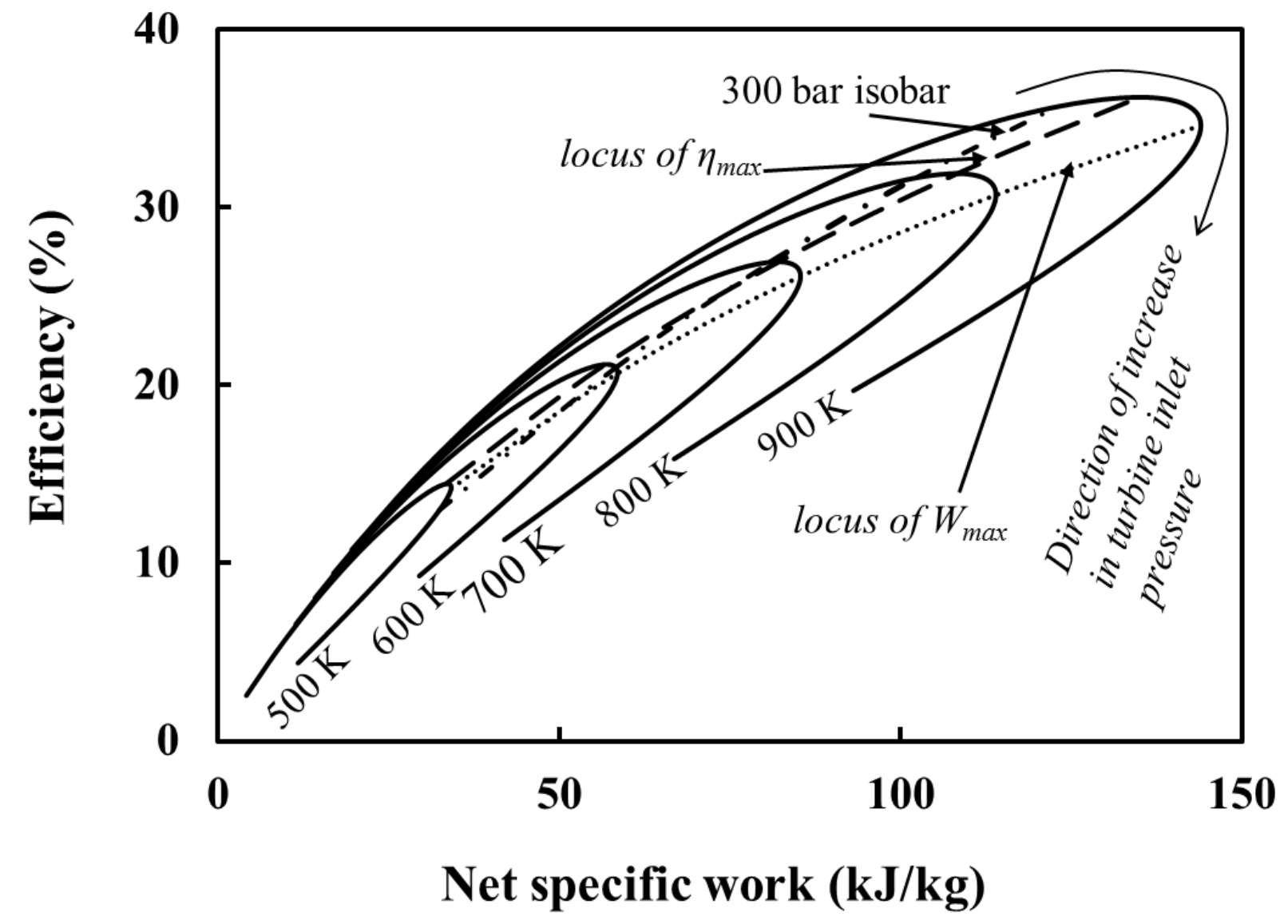

Figure 12. Efficiency- specific work plane for transcritical $\mathrm{CO}_{2}$ Rankine cycle with condensation at $300 \mathrm{~K}$. 

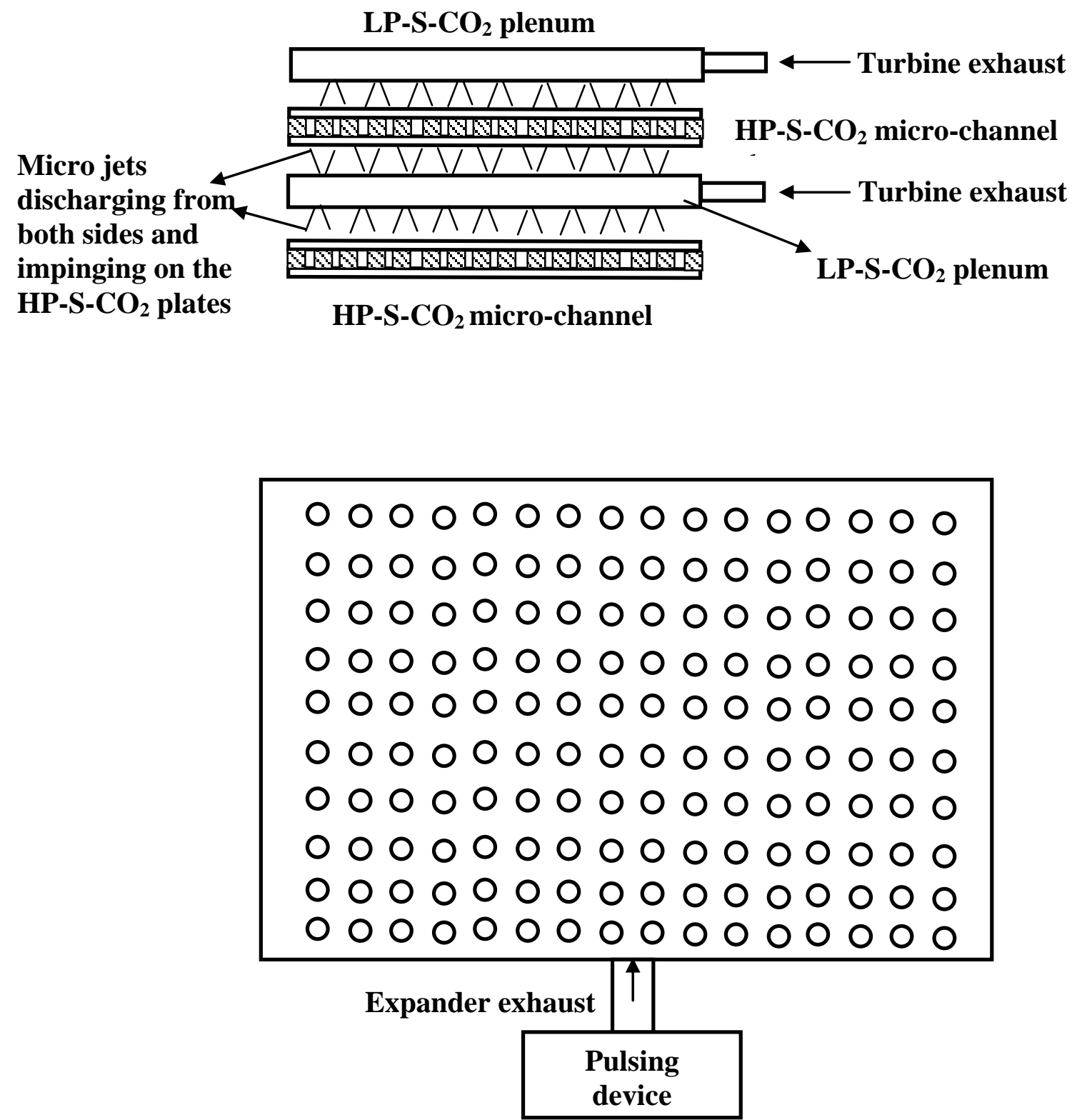

Figure 13. A possible configuration of regenerator for enhancing heat transfer through pulsed impinging jets. 